\title{
Dynamics of miR156 and miR172 involved in the flowering of Jatropha
}

\section{curcas L.}

\section{Adriana Sánchez-Gutiérrez', Isidro Ovando-Medina1', Lourdes Adriano-Anaya', Alfredo Vázquez-Ovando and Miguel Salvador-Figueroa*}

Received: May 11, 2017

Accepted: September 25, 2017

\begin{abstract}
Jatropha curcas is a plant that accumulates high-quality oil in its seeds, which is capable of being transformed into liquid biofuel. However, several aspects of its flowering are still unknown, which is a key step in the production of fruits, seeds, and oil. Flowering is a complex process that is regulated by various factors at the molecular level, including microRNAs (miRNAs). There is evidence suggesting that the miRNAs of the miR156 and miR172 families play a key role in the flowering transition of plants. For this reason, the dynamics of miR156 and miR172 were studied during a production cycle of $J$. curcas. Our results reveal that $J$. curcas has a mechanism for the expression of these miRNAs that differs from that reported for the vast majority of angiosperms, since the expression of both families of miRNAs was positively correlated with the phenological state of $J$. curcas. We discuss the implications of these findings and how the regulatory mechanisms of miR156 and miR172 differ from what has been reported thus far.
\end{abstract}

Keywords: flowering, Jatropha curcas, miR156, miR172, miRNAs

\section{Introduction}

Jatropha curcas is a plant that accumulates high-quality oil in its seeds, which is useful for the production of liquid biofuels (Berchmans \& Hirata 2008; Abou-Kheira \& Atta 2009). The presence of toxic substances in its oil (Makkar et al. 2008) and its ability to withstand periods of drought and low soil fertility (Abou-Kheira \& Atta 2009; OvandoMedina et al. 2009; Divakara et al. 2010) make this plant advantageous for establishing plantations in areas not suitable for conventional crops (Openshaw 2000; Achten et al. 2008; Kumar \& Sharma 2008). However, commercial cultivation of this plant faces several obstacles due to the lack of knowledge regarding basic aspects of its physiology and phenology.

Although the phenological stages of angiosperms are diverse, flowering (duration, cycles, and season) is key to seed production. In the humid tropics, the beginning of flowering of J. curcas coincides with the rainy season (Raju \& Ezradanam 2002; Noor et al. 2011), and has been reported to occur during up to three periods of the year (March-April, August and November) in southern Mexico accessions (Adriano-Anaya et al. 2016). Nevertheless, flowering of $J$. curcas is asynchronous because the plant does not bloom evenly.

The process of flowering is influenced by light, water, temperature, the amount of stored sugars and other

\footnotetext{
1 Instituto de Biociencias, Universidad Autónoma de Chiapas, Boulevard Principe Akishino, Colonia Solidaridad 2000, 30798, Tapachula, Chiapas, México

* Corresponding author: miguel.salvador@unach.mx
} 


\section{Adriana Sánchez-Gutiérrez, Isidro Ovando-Medina, Lourdes Adriano-Anaya, Alfredo Vázquez-Ovando and Miguel Salvador-Figueroa}

nutrients, phytohormones, RNAs and microRNAs (miRNAs), among other factors (Blümel et al. 2015). There is evidence suggesting that flowering may be regulated through miRNAs of the miR156 and miR172 families (Bartel et al. 2004; Gandikota et al. 2007; Sunkar \& Zhu 2007; Chen 2008; Voinnet 2009; Wu et al. 2009; Krol et al. 2010; Huntzinger \& Izaurralde 2011). In Arabidopsis thaliana, miR157 and miR156 negatively affects the posttranscriptional regulation of transcription factors SPL3, SPL4, and SPL5 in meristem; factors SLP10 and SPL15 in leaves; and SPL9 in both tissues, all of which are involved in flowering. Also, overexpression of miR156 is known to extend the expression of vegetative traits and cause delays in flowering (Wu \& Poethig 2006; Schwarz et al. 2008; Wu et al. 2009; Chuck et al. 2011).

Similarly, miR172 represses genes for the transcription factors Apetala (AP) AP1 and AP2, Target of Eat (TOE), TOE1, TOE2 and TOE3, Schlafütze (SMZ) and Schnarchzapfen (SNZ) (Aukerman \& Sakai 2003; Chen 2004)]. Plants lacking TOE1 and TOE2 are early blooming, while plants overexpressing TOE1, TOE2, SNZ, or SMZ are late blooming. Overexpression of miR172 in Arabidopsis accelerates flowering (Aukerman \& Sakai 2003; Schmid et al. 2003; Jung et al. 2007; Mathieu et al. 2009; Wu et al. 2009).

On the other hand, it has been shown that in A. thaliana miR156 regulates the expression of miR172 trough SPL9 (Wu et al. 2009). Decrease in the expression of miR156 leads to the increase of SPL9, and thus to the increase of miR172b, which results in flowering (Mathieu et al. 2009; Wu et al. 2009; Yant et al. 2010). Likewise, it has been reported that some miRNAs of families 156 and 172 are related to switching from the vegetative to the reproductive stage of development. In this sense, the expression of miR172a, $\mathrm{b}$ and $\mathrm{c}$ genes in Arabidopsis increases as the reproductive stage is reached, whereas the miR172d gene is not altered (Jung et al. 2007). Studies in Ricinus communis showed that miRNAs $156 \mathrm{a}$, d, and e are associated with SPL genes (Zeng et al. 2010).

For J. curcas, auxin response factor (ARF), pentatricopeptide repeat gene (PPR), and the element responsible for the dehydration of C-repeat (DRE / CRT) were reported as possible targets of miR156 a, b and c, isolated from seeds. However, the aforementioned study did not report whether the target genes of these variants of miR156 are involved in the vegetative-reproductive transition of the plant (Galli et al. 2014). Although a large number of miRNAs have been identified in various plants (Zeng et al. 2010; Wang et al. 2011; 2012; Vishwakarma \& Jadeja 2013), only two studies have reported and validated the existence of miR156 and miR172 in J. curcas (Zeng et al. 2010; Galli et al. 2014). This suggests the possibility that this pair of miRNAs is involved in the flowering of J. curcas. The aim of this study was to determine the dynamics of miR172 and miR156 during the different stages of growth of J. curcas L.

\section{Materials and methods}

\section{Extraction of miRNAs}

For this study, plants raised from seeds of the MAP08 accession of $J$. curcas, belonging to the collection at the Germplasm Bank of the Instituto de Biociencias at the Universidad Autonoma de Chiapas, were used. The plants were cultivated under field conditions in $20 \mathrm{~kg}$ pots containing a mixture of sandy loam soil with vermicompost (ratio 20:1 kg dry weight) and 0.2\% total nitrogen. Sampling was carried out once a month during the vegetative phase of plant growth (five samples) and once a week as they approached flowering. Extraction of the miRNAs was performed using the mirPremier ${ }^{\circledR}$ microRNA Isolation kit (SIGMA-ALDRICH ${ }^{\circledR}$, USA), starting with the presence of mature meristems and leaves. Plant samples were transported on ice from the field to the laboratory and processed immediately.

\section{Polyadenylation and CDNA synthesis}

miRNAs were adenylated with $5 \mathrm{U}$ of Escherichia coli poly (A) polymerase (New England BioLabs ${ }^{\circledR}$ ) by incubation at $37{ }^{\circ} \mathrm{C}$ for $1 \mathrm{~h}$. The products were purified using a phenol:chloroform mix (1:1 v/v) and $2 \mathrm{mg} \mathrm{mL}^{-1}$ of glycogen.

\section{Design of initiators and adapters}

The miRNAs selected for this study were miR172, with variants a, b, c, and d, and miR156 a, b, c, and d, for both $3 p$ and $5 p$ chains. For the variants, or isomiRNAs, from the miR172 family, two pairs of initiators were selected since only the mature sequence of isomiR172d exhibits variation and a pair of initiators was required to study the miR156 mature miRNAs.

The adapters and initiators used were those proposed by Zeng et al. (2010) for Ricinus communis L. The sequence of the adapters was modified at the 3 ' end by adding seven complementary bases to the mature sequence of each variant of the miRNAs studied. The expected size of the amplicon was about $80 \mathrm{bp}$. The initiators were labeled at the 5' end with D2, D3, or D4 WellRED ${ }^{\circledR}$ flourophores (Beckman Coulter ${ }^{\circledR}$, Inc. USA). A normalizer gene, the U6 sRNA with constitutive expression, was used. To accomplish this, multiple sequence alignments of mRNA genes of seven species, including $A$. thaliana, were performed using the CLUSTAL W 2.1 program (Thompson et al. 1994), and a highly-conserved region was selected. For amplifications, an anchor initiator with a sequence complementary to the known sequence of the adapters was used. Sequences are described in Table I. 
Table I. Initiator and adapter sequences.

\begin{tabular}{|l|l|l|}
\hline \multicolumn{1}{|c|}{ miRNA ID } & \multicolumn{1}{|c|}{ Initiator } & \multicolumn{1}{c|}{ Adapter poly (T) without marking } \\
\hline miR156-3p & D3-tgacagaagagagtgagcaca & GCTGTCAACGATACGCTACGTAACGGCATGACAGTG(T)24(TGTGCTC) \\
\hline miR156-5p & D4-actgtcttctctcactcgtgt & GCTGTCAACGATACGCTACGTAACGGCATGACAGTG(T)24(ACACGAG) \\
\hline miR172d-5p & D3-ggaatcttgatgatgctgcag & GCTGTCAACGATACGCTACGTAACGGCATGACAGTG(T)24(CTGCAGC) \\
\hline miR172d-3p & D4-ccttagaactactacgacgtc & GCTGTCAACGATACGCTACGTAACGGCATGACAGTG(T)24(GACGTCG) \\
\hline miR172abc-5p & D3-agaatcttgatgatgctgcat & GCTGTCAACGATACGCTACGTAACGGCATGACAGTG(T)24(ATGCAGC) \\
\hline miR172abc-3p & D4-tcttagaactactacgacgta & GCTGTCAACGATACGCTACGTAACGGCATGACAGTG(T)24(TACGTCG) \\
\hline U6 & D2-acagagaagattagcatggcc & GCTGTCAACGATACGCTACGTAACGGCATGACAGTG(T)24(CGTTACG) \\
\hline Anchorage & tgtcaacgatacgctacgtaacg & \\
\hline
\end{tabular}

\section{Synthesis of cDNA and amplified products}

Both cDNAs and the amplified products were obtained following the protocols suggested by Zeng et al. (2010) as follows. For cDNA, the adenylated products $(800 \pm 50 \mathrm{ng})$ were incubated together with poly $\mathrm{T}(25 \mathrm{pmol})$ adapters for $5 \mathrm{~min}$ at $70^{\circ} \mathrm{C}$ for denaturation, and then for $5 \mathrm{~min}$ at $37^{\circ} \mathrm{C}$ to align the adapters. They were then cooled in ice and incubated for one hour at $37^{\circ} \mathrm{C}$ with $5 \mathrm{U}$ of M-MLV reverse transcriptase (Promega, USA).

For amplification, we used a reaction mixture of 2 $\mu \mathrm{L}$ cDNA, $2 \mu \mathrm{L}$ of $25 \mathrm{mM} \mathrm{MgCl}, 0.1 \mu \mathrm{L}$ of $10 \mathrm{mM}$ dNTP mix (Promega, EUA), $2.5 \mathrm{U}$ of GoTaq ${ }^{\circledR}$ DNA Polymerase (Promega, EUA), $2.5 \mu \mathrm{L} 10 \mathrm{X}$ buffer, $12 \mathrm{pmol}$ of the labeled initiator and $12 \mathrm{pmol}$ of the first anchorage, adjusting to a volume of $25 \mu \mathrm{L}$ with milli-Q water. The amplification protocol consisted of an initial temperature of $94^{\circ} \mathrm{C}$ for 5 min, 30 cycles of $94^{\circ} \mathrm{C}$ for $30 \mathrm{~s}$, a period of $30 \mathrm{~s}$ at 58 or $60^{\circ} \mathrm{C}$ for annealing, depending on the initiator, and a period of $30 \mathrm{~s}$ at $72^{\circ} \mathrm{C}$ for extension. A final extension cycle at $72^{\circ} \mathrm{C}$ for 7 min was done before storing at $4{ }^{\circ} \mathrm{C}$.

\section{Resolution of amplified fragments}

To validate the use of the initiators, preliminary tests were done with $R$. communis. The amplified fragments were resolved on $12 \%$ polyacrylamide gels.

The amplified products were resolved by capillary electrophoresis on a CEQ800 ${ }^{\circledR}$ automatic analyzer (Beckman Coulter, USA). To accomplish this, a $2 \mu \mathrm{L}$ sample and a $0.25 \mu \mathrm{L}$ of the $400 \mathrm{bp}$ molecular weight marker labeled with WellRed ${ }^{\circledR}$ D1 fluorophore (Beckman Coulter (C), Inc. USA) were mixed and adjusted to $30 \mu \mathrm{L}$ with SLS (Sample Loading Solution). The electrophoretic conditions were: capillary temperature of $50{ }^{\circ} \mathrm{C}$, denaturation temperature of $90^{\circ} \mathrm{C}$, injection voltage of $2.0 \mathrm{kV}$ and a separation voltage of $5.0 \mathrm{kV}$, for one hour. To determine the size of fragments, the electropherograms were calibrated with the molecular weight marker of $400 \mathrm{bp}$ (confidence level > $99 \%$ ). The electropherograms obtained were considered only when the correlation coefficient of the marker was at least 0.99.
The resolution of the samples was done in duplicate and was accepted only when the replicates yielded the same result. In addition, the effect of each fluorophore on signal intensity was considered; in order to eliminate this variable, recommendations described in the Beckman Coulter( $)$, Inc. GenomaLab ${ }^{\circledR}$ Fragment Analysis Protocol were followed.

\section{Semi-quantitative analysis of miRNA expression}

Expression dynamics were determined for each analyzed isomiRNA. To calculate the relative expression, the area under the curve obtained from each miRNA in capillary resolution was used and normalized with U6 expression. The areas were calculated exclusively for the highest peaks of the expected size for each miRNA, without taking into account smaller peaks corresponding to "stuttering" fragments. The expression level corresponding to the first sampling date was set to 1 .

To show abrupt changes in the expression of each of the miRNAs studied, which could be used as evidence to establish the relationship between the expression of miRNAs and floral transition, we used the procedure for the most likely number of groups (Evanno et al. 2005). This procedure makes evident abrupt changes in the slope of a trend. To do so, the mean level of expression for each sampling point was plotted, and the differences between the mean of each sampling point and the mean of the values of successive points were plotted. Finally, the final differences obtained among the standard deviations of each sampling point were plotted.

\section{Results and discussion}

\section{Resolution of amplified fragments}

All initiators yielded amplicons of the expected size, approximately $80 \mathrm{bp}$, in both $R$. communis and $J$. curcas (Fig. 1A-B). The resolution of the fragments in capillary electrophoresis confirmed that the amplicons ranged in size from 72 and $75 \mathrm{bp}$ for miRNAs, and were $74 \mathrm{bp}$ for U6 (Fig. 1C). 


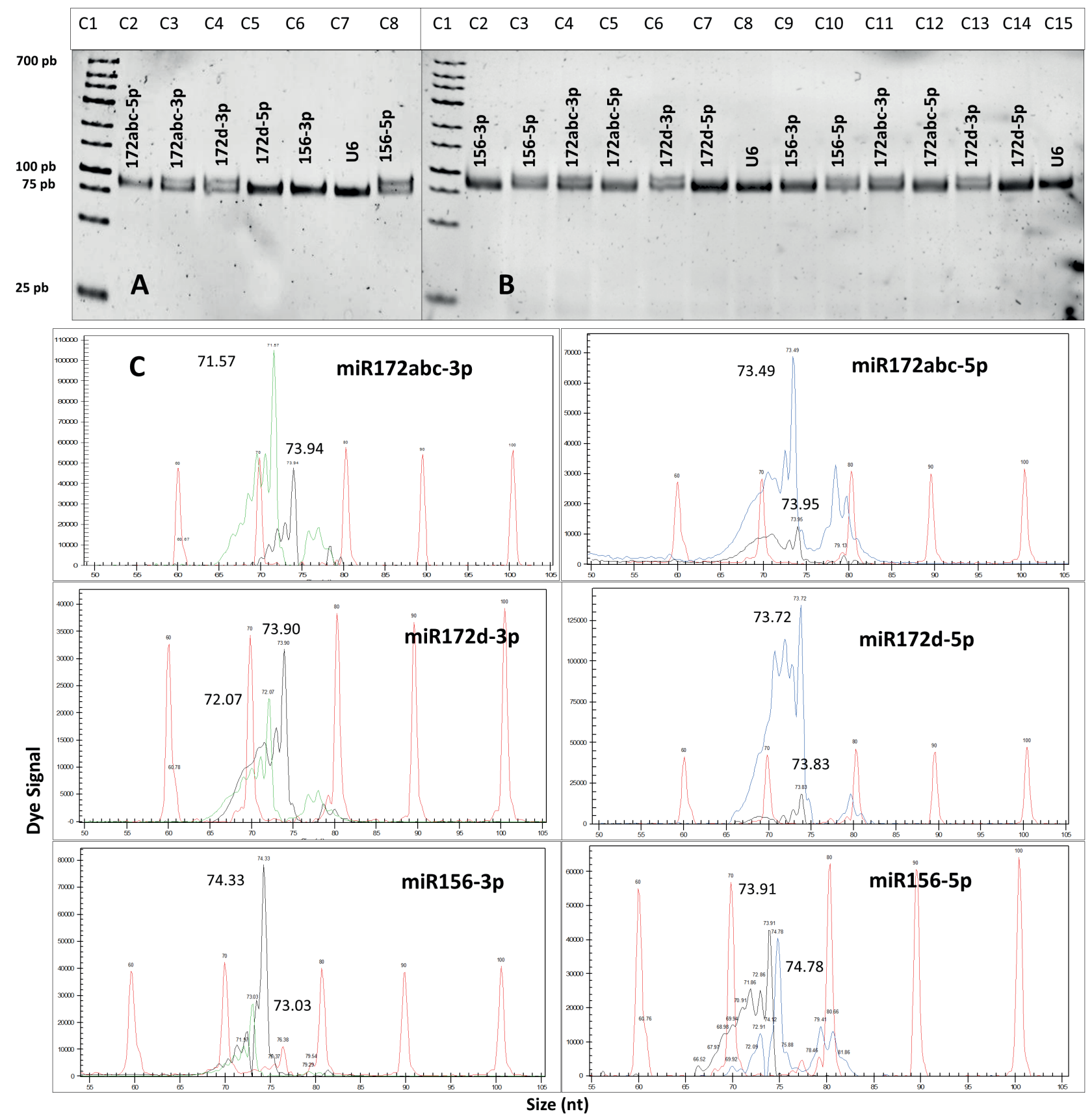

Figure 1. Resolution of the miRNAs of (A) R. communis and (B) J. curcas in $12 \%$ polyacrylamide gels. From R1 to R7 or J1 to J7 from leaves; from J8 to J14 of meristems. (C) Electropherograms of miRNAs of J. curcas. Molecular weight marker in red; U6 in black; miRNAs in green and blue. Please see the PDF file for colour reference.

\section{Expression analysis of miR172 and miR156}

In leaves and meristems, all miRNAs of the miR172 family showed differential expression as plants began to flower. However, the highest level of expression was reached at the transition from the vegetative stage to the reproductive stage. After flowering, the expression of these miRNAs decreased (Fig. 2).

On the other hand, the miR156 expression profile for both in leaves and meristems showed two main peaks, one in the first stage of the vegetative stage and the other at the beginning of the reproductive phase. In the meristems, the expression peak at the beginning of the reproductive phase was notably more pronounced, whereas in the leaves it was higher during the vegetative phase.

We found that during the reproductive stage of J. curcas, the relative expression of miR172abc-3p, miR172abc$5 \mathrm{p}, \mathrm{miR} 172 \mathrm{~d}-3 \mathrm{p}$, and miR172d-5p in meristems was, respectively, $4.55,0.53,0.04$, and 0.25 higher than to that observed in the leaves. On the other hand, during the 
A
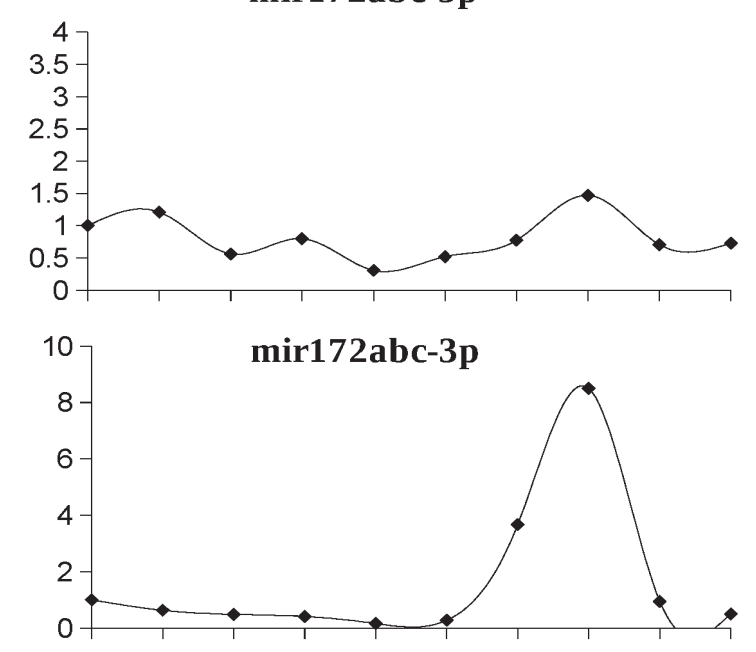

mir172d-5p
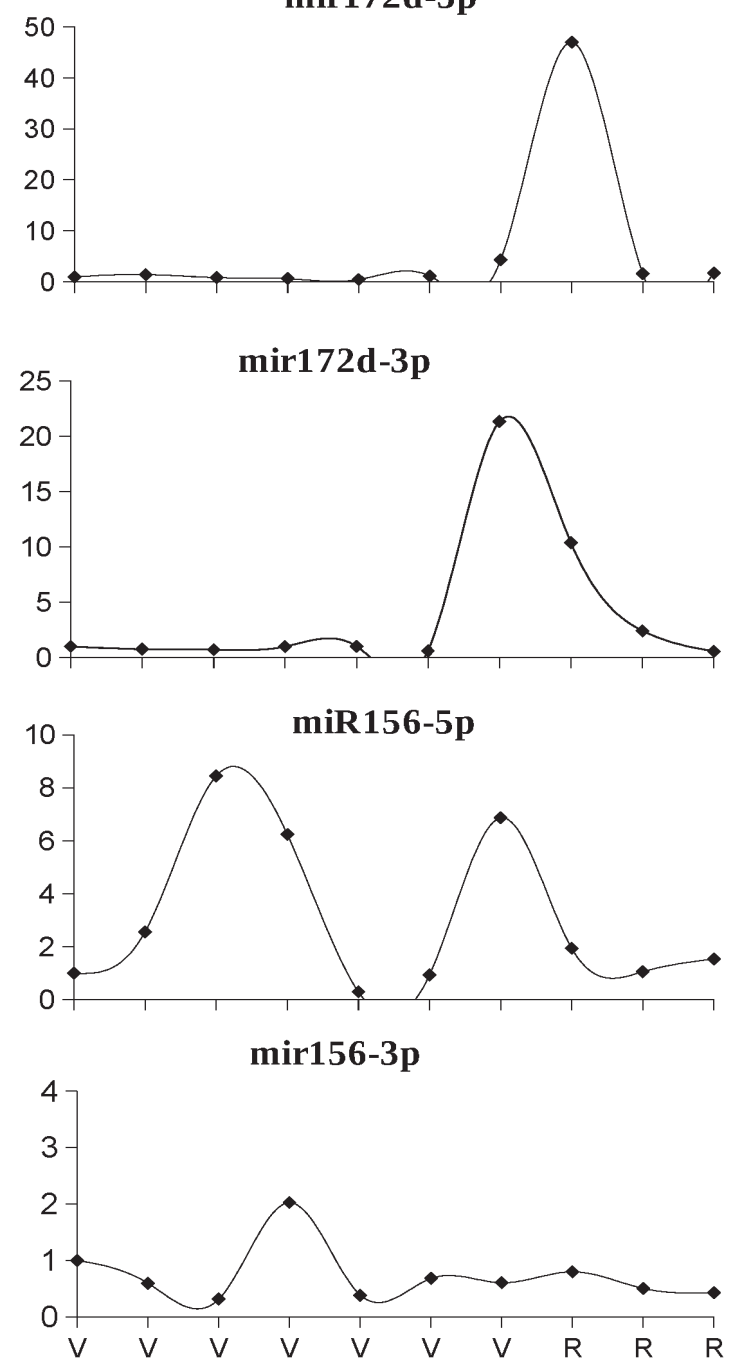

$\mathbf{B}$
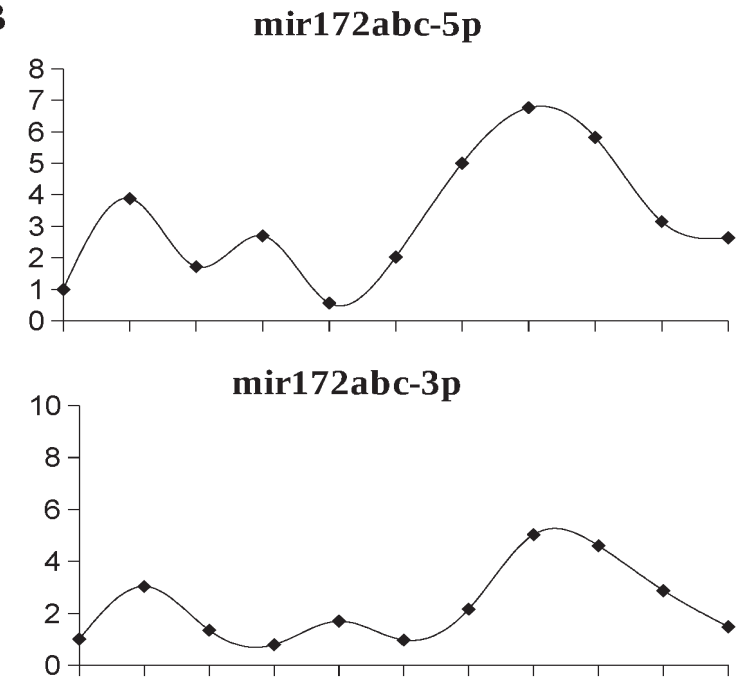

$\operatorname{mir172d-5p}$
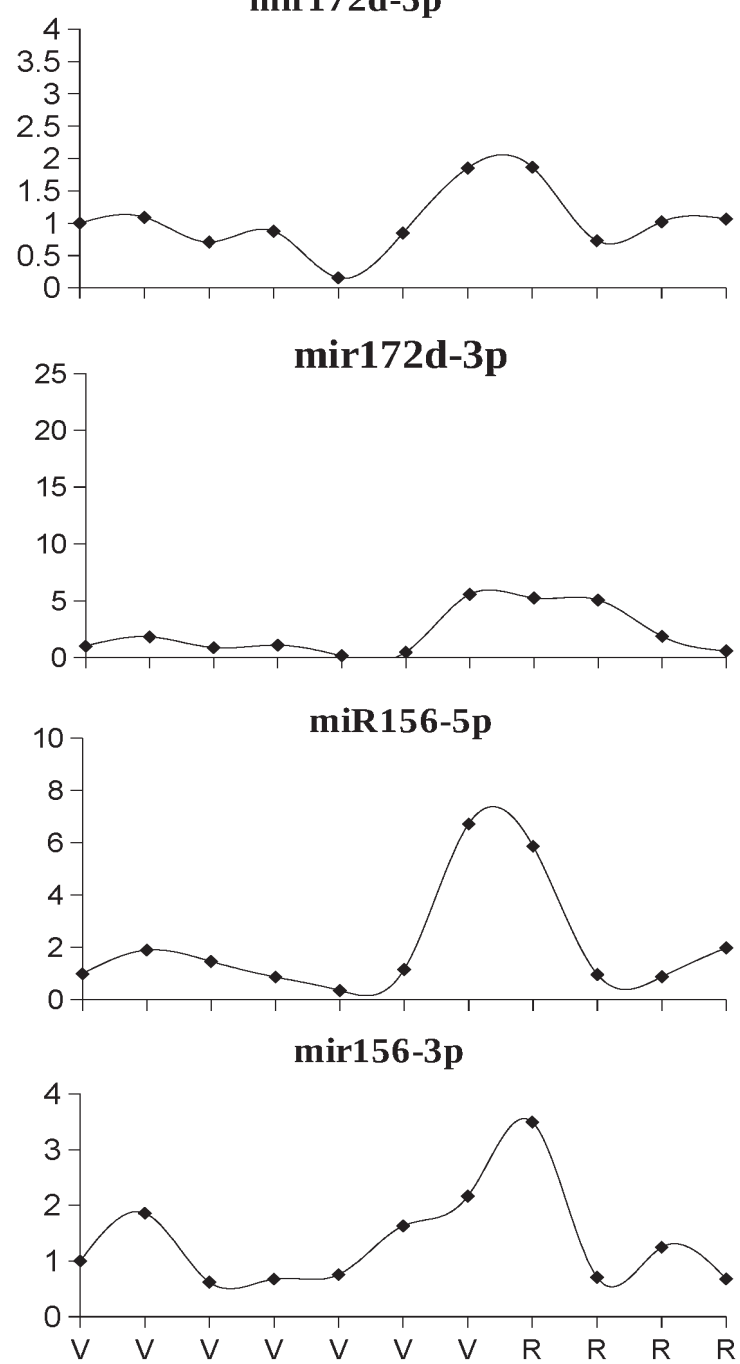

Figure 2. Relative expression (Y-axis) of the miR156 and miR172 families in leaves (A) and meristems (B) of J. curcas. V = vegetative, $\mathrm{R}$ = reproductive. 


\section{Adriana Sánchez-Gutiérrez, Isidro Ovando-Medina, Lourdes Adriano-Anaya, Alfredo Vázquez-Ovando and Miguel Salvador-Figueroa}

vegetative stage, the relative expression of miR156-5p and miR156-3p in meristems was 0.22 and 0.92 , respectively, relative to the leaf, whereas during the reproductive stage, it was 1.06 and 4.76 .

Based on these findings, three possible explanations for the expression of these miRNAs in the two studied tissues are proposed. The first possible explanation implies that both miRNAs were generated in both tissues (meristems and leaves) independently, and at the time of floral transition they increased their level of expression. This was the case with miR172, which increased its level of expression in both leaves and meristems at the time of the vegetative to reproductive transition. In the case of miR156, the expression was temporally different in each tissue. In leaves, it had a peak expression in the vegetative stage and another at the time of floral transition, whereas in meristems it only had increased expression at the floral transition. Temporal tissue expression has already been described in J. curcas seeds, and each isomiRNA, for both miR172 and miR156, is expressed to different levels depending on the degree of their maturity (Galli et al. 2014).

The second possible explanation implies that the miRNAs are generated in the leaves and travel through the vascular bundles to the apical meristems, where they accumulate. This would explain what happened during the reproductive stage with in miR172abc-3p, miR172d$5 p$, mir172d-3p, and miR156-5p, whose expression was greater in leaves. It also suggests that during transport, these miRNAs are susceptible to degradation, probably due to small RNA degrading nucleases (SDNs), as in Arabidopsis, or by intervention of the HEN1 suppressor gene (supressor-1, HESO1). This is a nucleotidyl-transferase that adds uracil queues at the 3' end of the unmethylated miRNAs, thus promoting their degradation (Ramachandran \& Chen 2008; Ren et al. 2012; Zhao et al. 2012), which would explain the lower level of expression found in meristems. In Arabidopsis, miR172 and miR156 have been observed in vascular bundles of adult plants (Buhtz et al. 2010), which demonstrate the existence of miRNA transport.

However, this second possible explanation does not explain what happened with miR172abc-5p and miR156$3 p$, whose expression was 4.55 and 4.76 times greater in meristems than in leaves in the reproductive stage. This indicates that these isomiRNAs are probably being generated primarily in the meristems. This does not, however, necessarily invalidate the possibility of their transport from the leaves to the meristems, but does support the idea that their expression may be tissue-specific. It is known that the expression of miRNAs in other plants depends on the type of tissue analyzed. For instance, in rice, miR172c is expressed in seedlings but not in grains under development, and in Phalaenopsis hybrida, the PhmiR172-1 and PhmiR172-2 variants were detected in stems, pedicels, roots, and meristems, but not in leaves, petals, and sepals (Sunkar et al. 2008; Zhu et al. 2008; Han et al. 2014).
The third, and most likely, possible explanation suggests that both miRNAs are synthesized in both leaves and meristems, and also transported through vascular bundles from the leaves to the apical meristems, thereby facilitating the floral transition. This possibility is supported by the fact that the level of expression for each isomiRNA differs depending on the tissue in which it is found. In addition, despite the possibility of transport, the expression of most miRNAs was lower in meristems than in leaves, with the exception of miR172abc-5p and miR156-3p. This confirms that the expression of miRNAs depends on the variant of miRNA analyzed, and the tissue from where it came (Jung et al. 2007; Zeng et al. 2010; Galli et al. 2014).

Analyses of the expression of miR172 and miR156 using the procedure of Evanno et al. (2005) produced results similar to those previously described (Fig. 1C). It was also observed that in J. curcas, both miR172d and miR172abc exhibited increased expression with phenological stage of the plant. This contrasts with Arabidopsis, where miR172d expression was not altered (Jung et al. 2007; Zhu \& Helliwell 2011).

Previous research (Galli et al. 2014) has failed to show SPL genes to be targets of J. curcas miR156, or any other gene linked to floral transition, but reported the existence of a positive relationship between the expression of miR156 and floral transition, which was more evident in meristematic tissue than in mature leaves. This result was not expected, since miR156 expression decreases with reproductive development in other plants (Aukerman \& Sakai 2003; Jung et al. 2007; Wu et al. 2009; Chuck et al. 2011; Zhu \& Helliwell 2011; Wang et al. 2012; Levy et al. 2014).

Other genes that regulate flowering in Arabidosis behave differently in J. curcas. The homologous isolated J. curcas gene APETALA1 (JcAP1) overexpressing in Arabidopsis, significantly increased the expression of TFL1 and promoted early flowering. However, when overexpressed in J. curcas, there were no changes in JcTFL genes nor in flowering time (Tang et al. 2016).

The regulation of this pair of miRNAs in J. curcas seems to be different in leaves than in meristems. It has been reported that, in Arabidopsis leaves, the expression of miR172 is regulated by the action of SPL9 and most likely SPL10 and SPL15 (Wu et al. 2009; Zhu \& Helliwell 2011). Findings in J. curcas leaves allow us to infer that SPL9 is inhibited by the action of miR156 during the vegetative stage of the plant. However, a drastic decrease in the expression of miR156 in the early stages of flowering is observed, suggesting the expression of SPL9. Afterwards, though, the expression of miR156-5p increases again. This temporary decrease in expression might have been sufficient for SPL9 to promote miR172 expression, leading to floral transition.

In meristems, the expression of miR156 exhibited a small peak in the early stages of plant development, which may be allowing low levels of expression of SPL9 during the vegetative stage, which would explain the change 
in expression of miR172 during that period. Although the increased expression of miR156 was considerable at flowering, it is likely that the level of expression of SPL9 achieved was sufficient to regulate the expression of miR172. It is also possible that, in J. curcas, SPL genes are not regulated by miR156, or that they are not directly involved in the regulation of flowering. To dismiss these hypotheses, studies on the expression of miR156 targets throughout the reproductive cycle of J. curcas are needed.

\section{Conclusion}

The miRNA expression patterns observed in this study with $J$. curcas do not coincide with the trends reported for other plants, where the expression of miR156 and miR172 are inversely related. However, a positive relationship was observed between the expression of both miRNA families and the onset of flowering. This shows that although miR156 and miR172 are involved in the floral transition of J. curcas, their regulatory mechanisms are different from what has been reported thus far. Further studies of these two miRNAs in different tissues and vascular bundles are needed in order to elucidate whether the miRNAs are generated in one or both tissues, and how much of them are transported through the vascular system.

\section{References}

Abou-Kheira A, Atta N. 2009. Response of Jatropha curcas L. to water deficit: Yield, water use efficiency and oilseed characteristics. Biomass \& Bioenergy 33: 1343-1350.

Achten WMJ, Verchot L, Franken YJ, Mathijs E, Singh, VP, Aerts R. 2008. Jatropha biodiesel production and use. Biomass \& Bioenergy 32: 1063-1084.

Adriano-Anaya ML, Pérez-Castillo E, Salvador-Figueroa M, et al. 2016. Sex expression and floral diversity in Jatropha curcas: a population study in its center of origin. PeerJ 4: e2071. doi: 10.7717/peerj.2071.

Aukerman MJ, Sakai H. 2003. Regulation of flowering time and floral organ identity by a microRNA and its APETALA2 -like target genes. Plant Cell 15: 2730-2741.

Bartel DP, Lee R, Feinbaum R. 2004. MicroRNAs: genomics, biogenesis, mechanism, and function genomics: The miRNA genes. Cell 116: 281-297.

Berchmans HJ, Hirata S. 2008. Biodiesel production from crude Jatropha curcas $\mathrm{L}$. seed oil with a high content of free fatty acids. Bioresource Technology 99: 1716-1721.

Blümel M, Dally N, Jung C. 2015. Flowering time regulation in crops-What did we learn from Arabidopsis? Current Opinion in Biotechnology 32: 121-129.

Buhtz A, Pieritz J, Springer F, Kehr J. 2010. Phloem small RNAs, nutrient stress responses, and systemic mobility. BMC Plant Biology 10: 64-77.

Chen X. 2004. MicroRNA as a translational repressor of APETALA2 in Arabidopsis flower development. Science 303: 2022-2025.

Chen X. 2008. MicroRNA metabolism in plants. Current Topics in Microbiology Immunology 320: 117-136.

Chuck GS, Tobias C, Sun L, et al. 2011. Overexpression of the maize Corngrass 1 microRNA prevents flowering, improves digestibility, and increases starch content of switchgrass. Proceedings of the National Academy of Sciences 108: 17551-17555.

Divakara BN, Upadhyaya HD, Wani SP, Laxmipathi G. 2010. Biology and genetic improvement of Jatropha curcas L. Applied Energy 87: 732-742.
Evanno G, Regnaut S, Goudet J. 2005. Detecting the number of clusters of individuals using the software STRUCTURE: a simulation study. Molecular Ecology 14: 2611-2620.

Galli V, Guzman F, Oliveira LFV, et al. 2014. Identifying microRNAs and transcript targets in Jatropha seeds. PLoS ONE 9(2): 1-10 e83727. doi: 10.1371/journal.pone.0083727.

Gandikota M, Birkenbihl RP, Hmann SH, Cardon GH, Saedler H, Huijser P. 2007. The miRNA156/157 recognition element in the 3' UTR of the Arabidopsis SBP box gene SPL3 prevents early flowering by translational inhibition in seedlings. Plant Journal 49: 683-693.

Han YY, Yan QH, Ming F. 2014. An effective homologous cloning method for isolating novel miR172s from Phalaenopsis hybrid. Genetics and Molecular Biology 37: 414-422.

Huntzinger E, Izaurralde E. 2011. Gene silencing by microRNAs: contributions of translational repression and mRNA decay. Nature Reviews Genetics 12: 99-110.

Jung J, Seo Y, Seo PJ, et al. 2007. The GIGANTEA-Regulated MicroRNA172 Mediates Photoperiodic Flowering Independent of CONSTANS in Arabidopsis. Plant Cell 19: 2736-2748.

Krol J, Loedige I, Filipowicz W. 2010. The widespread regulation of microRNA biogenesis, function and decay. Nature Publishing Group 11: 597-610.

Kumar A, Sharma S. 2008. An evaluation of multipurpose oil seed crop for industrial uses (Jatropha curcas L.): a review. Industrial Crops and Products 28: 1-10.

Levy A, Szwerdszarf D, Abu-Abied M, et al. 2014. Profiling microRNAs in Eucalyptus grandis reveals no mutual relationship between alterations in miR156 and miR172 expression and adventitious root induction during development. BMC Genomics 15: 1-9.

Makkar HPS., Martínez-Herrera J, Becker K. 2008. Variations in seed number per fruit, seed physical parameters and contents of oil, protein and phorbol esters in toxic and non-toxic genotypes of Jatropha curcas. Journal of Plant Sciences 3: 260-265.

Mathieu J, Yant LJ, Mürdter F, Küttner F, Schmid M. 2009. Repression of flowering by the miR172 target SMZ. PLoS Biology 7: e1000148. doi:10.1371/ journal. pbio.1000148.

Noor NCA, Lee AT, Psyquay NAA. 2011. Flowering and fruit set under Malaysian climate of Jatropha curcas L. American Journal of Agricultural and Biological Sciences 6: 142-147.

Openshaw K. 2000. A review of J. curcas: an oil plant unfulfilled promise. Biomass \& Bioenergy 19: 1-15.

Ovando-Medina I, Adriano-Anaya M, Salvador-Figueroa M, Ruiz-Gonzalez S, Vázquez-Ovando A. 2009. Does biodiesel from Jatropha curcas represent a sustainable alternative energy source? Sustainability 1: 1035-1041.

Raju AJS, Ezradanam V. 2002. Pollination ecology and fruiting behavior in a monoecious species, Jatropha curcas L. (Euphorbiaceae). Current Science 83: 1395-1398.

Ramachandran V, Chen X. 2008. Degradation of microRNAs by a family of exoribonucleases in Arabidopsis. Science 321: 1490-1492.

Ren G, Chen X, Yu B. 2012. Uridylation of miRNAs by hen1 suppressor1 in Arabidopsis. Current Biology 22: 695-700.

Schmid M, Uhlenhaut NH, Godard F, et al. 2003. Dissection of floral induction pathways using global expression analysis. Development 130: 6001-6012.

Schwarz S, Grande AV, Bujdoso N, Saedler H, Huijser P. 2008. The microRNA regulated SBP-box genes SPL9 and SPL15 control shoot maturation in Arabidopsis. Plant Molecular Biology 67: 183-195.

Sunkar R, Zhu JK. 2007. Micro RNAs and Short-interfering RNAs in Plants. Journal of Integrative Plant Biology 49: 817-826.

Sunkar R, Zhou X, Zheng Y, Zhang W, Zhu JK. 2008. Identification of novel and candidate miRNAs in rice by high throughput sequencing. BMC Plant Biology 8: 25.

Tang M, Tao YB, Xu ZF. 2016. Ectopic expression of Jatropha curcas APETALA1 (JcAP1) caused early flowering in Arabidopsis, but not in Jatropha. PeerJ 4(4): e1969. doi: 10.7717/peerj.1969.

Thompson JD, Higgins DG, Gibson TJ. 1994. CLUSTAL W: improving the sensitivity of progressive multiple sequence alignment through sequence weighting, position-specific gap penalties and weight matrix choice. Nucleic Acids Research 22: 4673-4680. 


\section{Adriana Sánchez-Gutiérrez, Isidro Ovando-Medina, Lourdes Adriano-Anaya, Alfredo Vázquez-Ovando and Miguel Salvador-Figueroa}

Vishwakarma NP, Jadeja VJ. 2013. Identification of miRNA encoded by Jatropha curcas from EST and GSS. Plant Signaling \& Behavior 8: 1-13.

Voinnet O. 2009. Origin, biogenesis, and activity of plant microRNAs. Cell 136: 669-687.

Wang CM, Liu P, Sun F, Li L, Ye J, Yue GH. 2012. Isolation and identification of miRNAs in Jatropha curcas. International Journal of Biological Sciences 8: 418-29.

Wang JW, Park MY, Wang LJ, et al. 2011. miRNA control of vegetative phase change in trees. PLoS Genet 7(2): e1002012. doi: 10.1371/ journal.pgen.1002012.

Wu G, Park MY, Conway SR, Wang J, Weigel D, Scott R. 2009. The sequential action of miR156 and miR172 regulates developmental timing in Arabidopsis. Cell 138: 750-759.

Wu G, Poethig RS. 2006. Temporal regulation of shoot development in Arabidopsis thaliana by miR156 and its target SPL3. Development 133: 3539-3547.
Yant L, Mathieu J, Dinh TT, et al. 2010. Orchestration of the floral transition and floral development in Arabidopsis by the bifunctional transcription factor APETALA2. Plant Cell 22: 2156-2170.

Zeng C, Wang W, Zheng Y, et al. 2010. Conservation and divergence of microRNAs and their functions in Euphorbiaceous plants. Nucleic Acids Research 38: 981-995.

Zhao Y, Yu Y, Zhai J, et al. 2012. The Arabidopsis nucleotidyl transferase HESO1 uridylates unmethylated small RNAs to trigger their degradation. Current Biology 22: 689-694.

Zhu QH, Helliwell AC. 2011. Regulation of flowering time and floral patterning by miR172. Journal of Experimental Botany 62: 487-495.

Zhu QH, Spriggs A, Matthew L, et al. 2008. A diverse set of microRNAs and microRNA-like small RNAs in developing rice grains. Genome Research 18: 1456-1465. 